\title{
Quantitative Evaluation of the Ecosystem Services Value for the Source Region of the South-to-North Water Transfer Project (Middle Route)
}

\author{
Jian Tang ${ }^{1, a}$, Huiqun Cao ${ }^{1, b}$ and Wenliang Zhai ${ }^{1, c}$ \\ ${ }^{1}$ Yangtze River Scientific Research Institute, Wuhan 430010, China \\ atang0815@yeah.net, bchenjincrsri@163.com
}

\begin{abstract}
Keywords: the South-to-North Water Transfer Project; ecosystem services value; sustainable development

Abstract. Ecosystem services value for the source region of the middle Route Project of the South-to-North Water Transfer Project (SRMRP) was evaluated by using the market value, shade-price and opportunity-cost methods based on land use data in the year 2000. The results indicated that the total value of ecosystem services in the SRMRP was approximately 242.94 billion RMB (Chinese currency), of which, the direct and indirect values were 61.99 and 180.95 billion RMB, respectively. The values of the ecosystem service functions in the SRMRP go as follow: gas regulation > production supply $>$ soil conservation $>$ environment purification $>$ biodiversity conservation $>$ water conservation $>$ recreation and culture $>$ nutrient circulation. The order of the total values of ecosystem services for different ecosystems in the SRMRP is as follows: forest > farmland $>$ water area $>$ grassland. The values of the ecosystem services per unit area in the SRMRP are in the order as follows: water area $>$ grassland $>$ forest $>$ cultivated land.
\end{abstract}

\section{Introduction}

In the nature, energy and material exchange are continuous performed between the biomass and the inorganic environment, which has formed a relatively stable unified whole named the ecosystem. Ecosystem can provide essential requirements for human's survival and developmentand life-support services. Products and services provided by ecosystems and ecological processes are collectively referred to as ecosystem services ${ }^{[1]}$. Ecosystem services can be quantitative evaluated. Scientific and comprehensive evaluation the value of ecological systems can provide reliable decision-making basis for the region planning and development, and have an important role to promote the sustainable management of ecological systems. Ecosystem services evaluation is the main content of the Millennium Ecosystem Assessment. Ecosystem services evaluation therefore becomes the frontier and hot topic of the global ecosystem management and sustainable development research ${ }^{[2-4]}$.

The middle Route Project for the South-to-North Water Transfer Project, which aims to mitigate the severe water shortage in the north of China, is the largest water transfer project in the world. The SRMRP provides many important ecosystem services. In order to promote the sustainable development of resources and environment in the SRMRP, a large number of ecosystem service evaluation researches performed and provided the theoretical and data support for the establishment of incentive and compensation mechanisms of ecological and environment protection. According to land use data of the SRMRP in Henan Province, Bai evaluated the regional ecosystem services value increased by the ecological construction project was about 3.5 billion $\mathrm{RMB}^{[5]}$. Yan et al. evaluated the ecological service values of soil and water conservation projects in the central source region (Danjiangkou Reservoir region) were about 3.3 billion $\mathrm{RMB}^{[6]}$. Chen et al. analyzed the temporal and spatial change characteristics of ecological service value for the central source region ${ }^{[7]}$. These studies have evaluated the economic value of the ecosystem services for the SRMRP, and provided a solid basis for the sustainable development of regional ecological environment protection. However, previous studies focused on the ecosystem services evaluation of sub-basin or central source region in the MRP. There is short of ecosystem services evaluation of different ecosystems from the perspective of the entire SRMRP. Therefore, there is an urgent need to perform ecosystem services evaluation for the entire SRMRP to provide decision-making basis for maintaining a reservoir of purified water. 
In order to acquire a clear understanding of the important role of ecological system in the SRMRP, ecosystem services values for the forest, grassland, farmland and water area of the entire SRMRP was evaluated based on land use data in 2000. The research findings are expected to provide scientific basis for the management and protection of ecological environment in the SRMRP.

\section{Evaluation Indicator System}

According to characteristics and data of the ecosystem services in the SRMRP, evaluation indicator system of the SRMRP was established from the perspective of direct and indirect value (Table 1). The indicators of ecosystem service functions were mainly including: production supply, recreation and culture, gas regulation, soil conservation, nutrient circulation, water conservation, environment purification and biodiversity conservation. Feasible account methods are used to estimate the values of ecosystem service functions. The sum of the ecosystem service functions values is the total value of the ecosystem services in the SRMRP.

Table 1. Evaluation Indicator System of the Ecosystem Services in the SRMRP

\begin{tabular}{|c|c|c|c|c|c|c|c|c|}
\hline \multirow{2}{*}{$\begin{array}{l}\text { Ecosystem } \\
\text { type }\end{array}$} & \multicolumn{2}{|c|}{ Direct value } & \multicolumn{6}{|c|}{ Indirect value } \\
\hline & $\begin{array}{l}\text { Production } \\
\text { supply }\end{array}$ & $\begin{array}{c}\text { Recreation } \\
\text { and } \\
\text { culture }\end{array}$ & $\begin{array}{c}\text { Gas } \\
\text { regulation }\end{array}$ & $\begin{array}{c}\text { Soil } \\
\text { conservation }\end{array}$ & $\begin{array}{l}\text { Nutrient } \\
\text { circulation }\end{array}$ & $\begin{array}{c}\text { Water } \\
\text { conservation }\end{array}$ & $\begin{array}{l}\text { Environment } \\
\text { purification }\end{array}$ & $\begin{array}{l}\text { Biodiversity } \\
\text { conservation }\end{array}$ \\
\hline Forest & $\sqrt{ }$ & $\sqrt{ }$ & $\sqrt{ }$ & $\sqrt{ }$ & $\sqrt{ }$ & $\sqrt{ }$ & $\sqrt{ }$ & $\sqrt{ }$ \\
\hline Grassland & $\sqrt{ }$ & $\sqrt{ }$ & $\sqrt{ }$ & $\sqrt{ }$ & $\sqrt{ }$ & $\sqrt{ }$ & $\sqrt{ }$ & $\sqrt{ }$ \\
\hline $\begin{array}{l}\text { Cultivated } \\
\text { land }\end{array}$ & $\sqrt{ }$ & $\sqrt{ }$ & $\sqrt{ }$ & $\sqrt{ }$ & $\sqrt{ }$ & $\sqrt{ }$ & $\sqrt{ }$ & $\sqrt{ }$ \\
\hline Water area & $\sqrt{ }$ & $\sqrt{ }$ & l & $\sqrt{ }$ & / & $\sqrt{ }$ & $\sqrt{ }$ & $\sqrt{ }$ \\
\hline
\end{tabular}

\section{Account Methods}

3.1. Direct Value. Value of production supply and value from recreation and culture services in the SRMRP are estimated by the market price method ${ }^{[8]}$.

3.1.1. Indirect Value. Ecosystem regulates the balance of carbon dioxide and oxygen by photosynthesis that can fix carbon dioxide and release oxygen. According to the equation for photosynthesis, $1 \mathrm{~g}$ dry matter generated by photosynthesis can fix $1.63 \mathrm{~g}$ carbon dioxide and release $1.2 \mathrm{~g}$ oxygen. The amounts of carbon sequestration and oxygen emission were therefore obtained by calculating the dry matter generated by forest, grassland and cultivated land in the SRMRP. The values of the carbon sequestration and oxygen emission are evaluated by afforestation cost method. Then, the value from gas regulation services was the sum of the value of carbon dioxide sequestration and oxygen emission.

The value of soil conservation in the SRMRP is evaluated from the following aspects including reducing land abandonment, maintaining soil fertility and reducing sediment deposition. Reduction in the amount of soil erosion in the SRMRP was calculated through the difference between the potential and actual soil erosion amount of forest land, grassland and cultivated land. According to the thickness and density of soil in the SRMRP, the amounts of reducing land abandonment were calculated from the reduction amount of soil erosion. The amounts of reducing land abandonment from water area were calculated from the amount of sediment deposition in Danjiangkou reservoir. The value from reducing land abandonment was calculated by the opportunity-cost method. The soil fertility maintaining by soil conservation are calculated by the amounts of nitrogen, phosphorus and potassium contained in the reduction in soil erosion. The shadow-price method is employed to calculated values of maintaining soil fertility services from the forest, grassland and cultivated land in the SRMRP. According to the laws of soil movement in China's major river basin, 24\% sediment due to soil erosion will deposit in water. The value from the services of reducing sediment deposition was calculated by alternative engineering approach.

The accumulations of nitrogen, phosphorus and potassium in the dry matter generated by forest, grassland and cultivated land are used to characterize the nutrient circulation service. The shadow-price method is employed to calculated values of nutrient circulation service from the forest, 
grassland and cultivated land in the SRMRP. The values of water conservation services from forest and grassland were calculated by regulation of water quantity and water quality. The values of water conservation services from cultivated land and water area were calculated by the regulation of the water quantity. Regulation of water quantity was calculated by water balance method. The shadow-engineering and shadow-price methods are used to calculate values of regulation of water quantity and water quality, respectively. Removals of sulfur dioxide, nitrogen oxides, fluorides and dust are used to characterize environment purification services from forest, grassland and cultivated land. Shadow-engineering method is used to calculate the value of environment purification services from forest, grassland and cultivated land. Due to data availability, value of environment purification services from water area is calculated by the value of waste treatment from water area proposed by Xie et al. ${ }^{[8]}$. The value from biodiversity conservation services in the SRMRP is estimated by the market price method.

\section{Characteristics of Ecosystem Service Value in the SRMRP}

4.1. Composition of Ecosystem Service Value in the SRMRP. According to the evaluation results, the total value of ecosystem services in the SRMRP is 242.94 billion RMB, of which the direct and indirect values are 61.99 and 180.95 billion RMB, respectively. The direct and indirect values accounts for $25.5 \%$ and $74.5 \%$ of the total value, respectively. The indirect value of the ecological system in the SRMRP plays a leading role (Fig. 1).

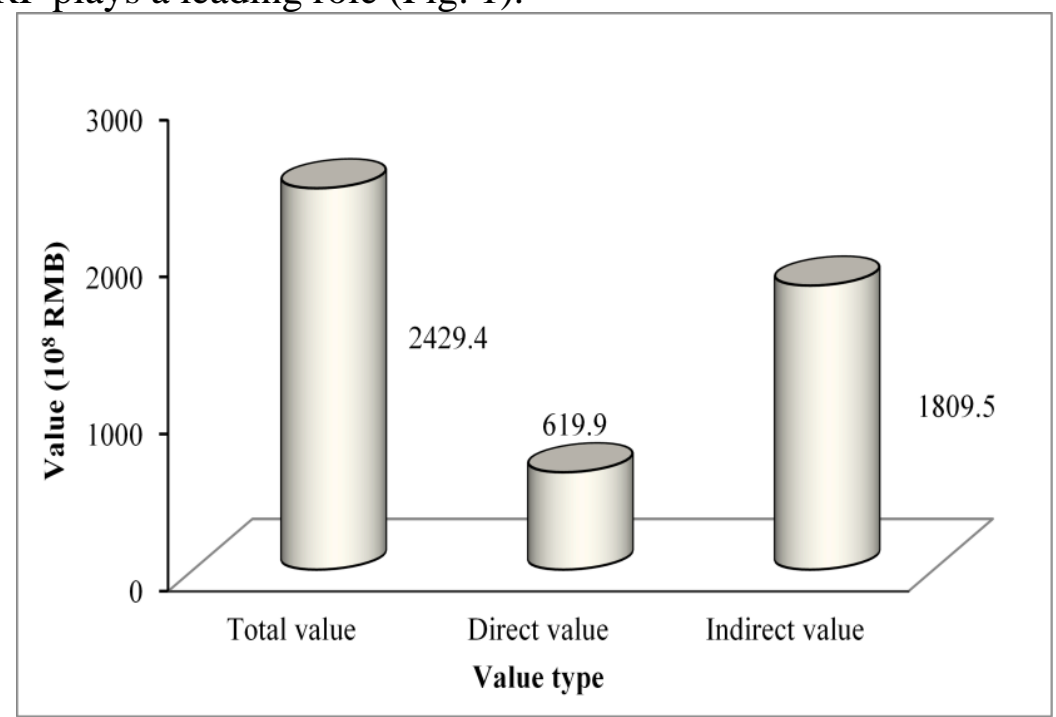

Fig. 1. Total Value of Ecosystem Services in the SRMRP

Composition of ecosystem service value in the SRMRP is shown in Fig. 2. As for the direct value, of which value of production supply services is $53.44 \mathrm{RMB}$, value of recreation and culture is 8.55 billion RMB. As for the indirect value, values of gas regulation, soil conservation, nutrient circulation, water conservation, Environment purification and biodiversity conservation services are 85.56, 27.09, $5.61,13.15,27.07$ and 22.47 billion RMB, respectively. The values of the ecosystem service functions in the SRMRP go as follow: gas regulation > production supply > soil conservation > environment purification $>$ biodiversity conservation $>$ water conservation $>$ recreation and culture $>$ nutrient circulation. Gas regulation, production supply and soil conservation play an important role in the ecosystem service value of the SRMRP. 


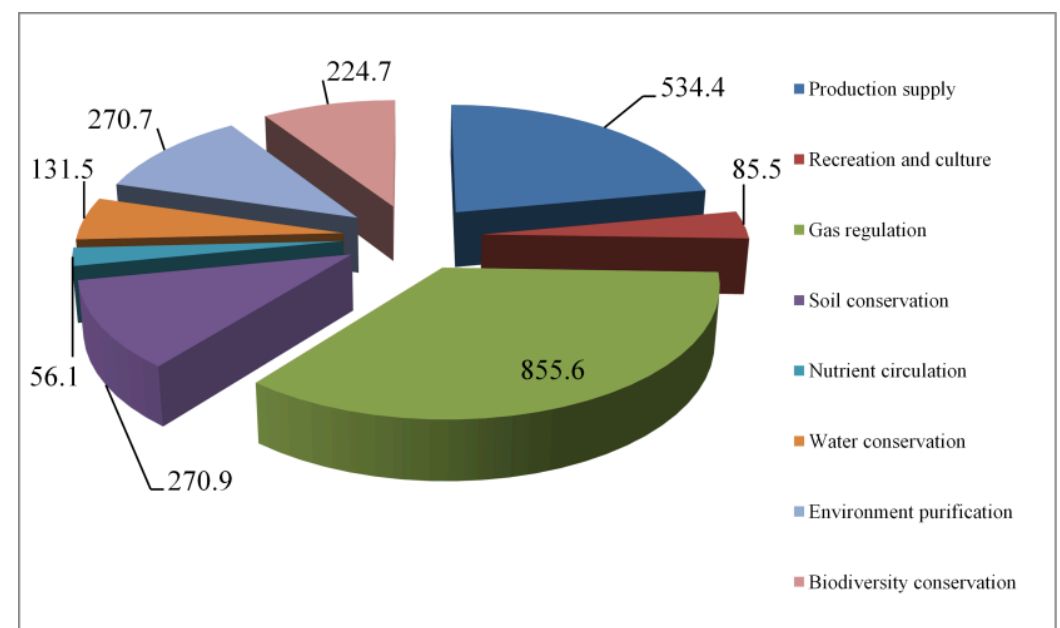

Fig. 2. Composition of Ecosystem Service Value in the SRMRP

4.1.1. Values of Ecosystem Services from Different Ecosystems in the SRMRP. The characteristics of ecosystem services value from forest, grassland, cultivated land and water area in the SRMRP are shown in Fig. 3. Ecological services value of forest ecosystem is 17.96 billion RMB, and accounts for $73.9 \%$ of the total value of Ecological services value in the SRMRP. Ecological services value of grassland ecological system is 11.33 billion RMB (4.7\%). Ecological services values of cultivated land and water area ecological system are $36.37(15 \%)$ and 15.64 (6.4\%) billion RMB. The order of the total values of ecosystem services for different ecosystems in the SRMRP is as follows: forest $>$ farmland $>$ water area $>$ grassland. The values of the ecosystem services per unit area in the SRMRP are in the order as follows: water area > grassland > forest $>$ cultivated land. The value of service function of each ecosystem is in the order: forest land > farmland > water area > grassland. Values of per unit area of forest, grassland, cultivated land and water area are 24.5, 25.2, 22.0 and 28.0 thousand $\mathrm{RMB} / \mathrm{hm}^{2}$, respectively. Resource development and management in the SRMRP should pay attention to the rational utilization and protection of forest and water resources.

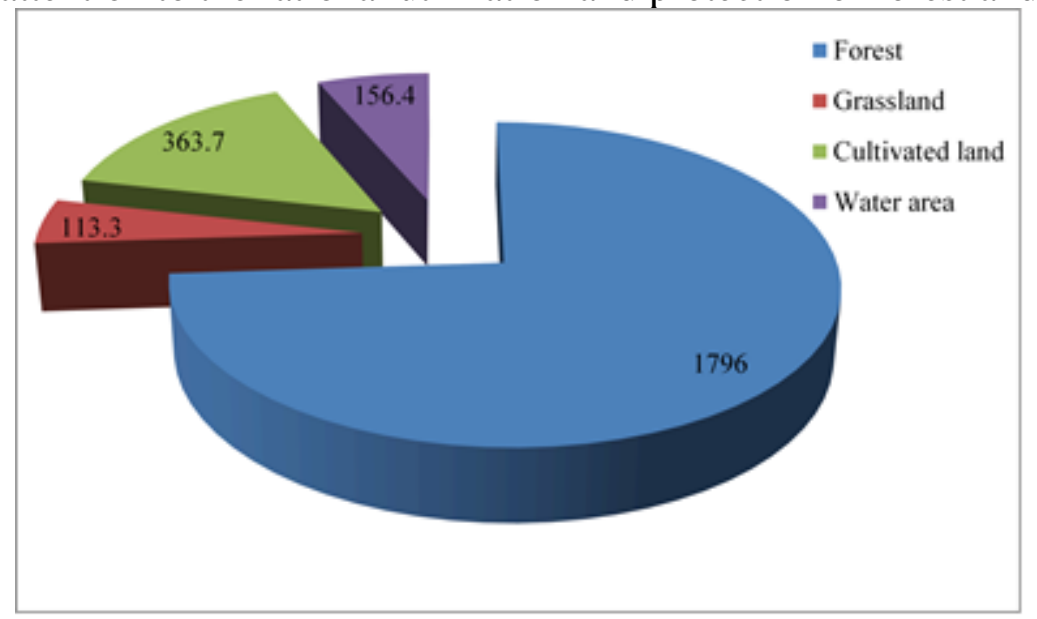

Fig. 3. Values of Ecosystem Services from Different Ecosystems

\section{Conclusions}

Ecosystem services value for the forest, grassland, cultivated land and water area of the entire SRMRP was evaluated by using the market value, shade-price and opportunity-cost methods based on land use data in the year 2000. The following results are obtained:

(1) The total value of ecosystem services in the SRMRP is 242.94 billion RMB, of which the direct and indirect values are 61.99 and 180.95 billion RMB, respectively. The direct and indirect values accounts for $25.5 \%$ and $74.5 \%$ of the total value, respectively.

(2) The values of the ecosystem service functions in the SRMRP go as follow: gas regulation > production supply $>$ soil conservation $>$ environment purification $>$ biodiversity conservation $>$ water conservation $>$ recreation and culture $>$ nutrient circulation. 
(3) The order of the total values of ecosystem services for different ecosystems in the SRMRP is as follows: forest $>$ farmland $>$ water area $>$ grassland. The values of the ecosystem services per unit area in the SRMRP are in the order as follows: water area > grassland > forest > cultivated land.

\section{Acknowledgements}

This work was financially supported by the National Natural Science Foundation of China (51609008), the Natural Science Foundation of Hubei Province (2015CFA157), and the Fundamental Research Funds for Central Public Welfare Research Institutes (CKSF2013015/SH \& CKSF2015015/SH).

\section{References}

[1] Holdren JP and Ehrlich PR: American Scientist. 62(1974), p. 282-292.

[2] Christie M, Fazey I, Cooper R, Hyde T and Kenter JO: Ecological economics, 83(2012), p. 67-78.

[3] Campagne CS, Salles JM, Boissery P and Deter J: Marine pollution bulletin. 97(2015), p. 391-400.

[4] Sgroi F, Foderà M, Dana LP, Mangiapane G, Tudisca S, Di Trapani AM and Testa R: Ecological Engineering. 90(2016), p. 399-404.

[5] Jingfeng Bai: Economic Geography. Vol. 30(2010), p. 657-661. (In Chinese)

[6] Fengling Yan, Xiaoyong Luo, Shaoping Lei, Liang Qiua and Hao Fan: Science of Soil and Water Conservation. Vol. 8(2010), p. 58-63. (In Chinese)

[7] Xiaolin Chen, Xiong He and Hai Liu: Journal of Central China Normal University. 49(2015), p. 434-439. (In Chinese)

[8] Gaodi Xie, Chunxia Lu, Yunfa Leng, Du Zheng and Shuangcheng Li: Journal of Natural Resources. 18(2003), p. 189-196. (In Chinese) 